\title{
Factors associated with institutional delivery in Dangila district, North West Ethiopia: a cross-sectional study.
}

\author{
Yeshalem Mulugeta Demilew ${ }^{1}$, Gebremedhin Berhe Gebregergs ${ }^{2}$, Azezu Asres Negusie ${ }^{3}$
}

1. School of Public Health, College of Medicine and Health Science, Bahir Dar University

2. School of Public Health, College of Health Science, Mekelle University

3. Midwifery Department, College of Medicine and Health Science, Bahir Dar University

\begin{abstract}
Introduction: Childbirth in a health institution has been shown to be associated with lower rates of maternal and neonatal mortality. However, about $85 \%$ of mothers in Ethiopia deliver at home.

Objective: To assess factors associated with institutional delivery service utilization among women who gave birth within one year prior to the study in Dangila district.

Methods: A cross-sectional study was conducted from February 01-28, 2015. A total of 763 mothers were interviewed using structured questionnaire. SPSS version 20 was used for analysis. Crude and adjusted Odds ratios were computed for selected variables. A P-value less than 0.05 was considered statistical significant.

Results: Only $18.3 \%$ of mothers gave birth at health facilities. Knowledge on danger signs [AOR=2.0, 95\% CI: (1.1, 3.4)], plan to give birth at health institution $[\mathrm{AOR}=5.4,95 \% \mathrm{CI}:(3.0,9.6)]$, having ANC follow up during pregnancy $[\mathrm{AOR}=12.9$, 95\% CI: $(5.0,33.3)]$ and time taken to get to a nearby health institution [AOR $=5.1,95 \%$ CI: $(2.9,9.1)]$ were associated with institutional delivery service utilization.

Conclusion: Institutional delivery was very low. Knowledge about danger signs, having ANC visits, and time were factors associated with institutional delivery service utilization. Thus, the findings recommend repeated re-enforcement of institutional delivery service utilization through professionals. And also, the findings recommend promotion of institutional delivery service utilization through mass media.
\end{abstract}

Keywords: unskilled personnel, skilled professional, delivery.

DOI: http://dx.doi.org/10.4314/ahs.v16i1.2

Cite as: Demilew YM, Gebregergs GB, Negusie AA. Factors associated with institutional delivery in Dangila District, North West Ethiopia: a cross-sectional study. Afri Health Sci. 2016;16(1): 10-17. http:/ / dx.doi.org/10.4314/ahs.v16i1.2

\section{Introduction}

Although there are national and global efforts to reduce maternal morbidity and mortality nevertheless a significant number of mothers die because of pregnancy and child birth related causes. Worldwide, an estimated 287,000 maternal deaths occur every year; almost all $(99 \%)$ of them are from developing countries ${ }^{1}$.

In developing countries more than half of the women deliver at home, and this is common among the poor and rural dwellers ${ }^{2}$. Home deliveries are un-hygienic, attended by unskilled personnel and when intervention is

\section{Corresponding author:}

Yeshalem Mulugeta Demilew,

School of Public Health, College of

Medicine and Health Science, Bahir Dar University

E-mail: yeshalem_mulugeta@yahoo.com

GBG: bgebrish04@gmail.com

AZN: Azezunigu@yahoo.com required, it is usually late. In sub Saharan African, 74.7$89.9 \%$ of women in the lowest two wealth quartiles give birth at home ${ }^{3}$.

In Ethiopia, the maternal mortality ratio (MMR) is estimated to be 676 deaths per 100,000 live births. Women from rural areas and the less educated ones are less likely to give birth at health institution ${ }^{4}$. Lack of skilled attendance is considered as one of the major factors in maternal and neonatal mortality. During child birth, there are about 1.02 million intrapartum stillbirths, 904,000 intrapartum-related neonatal deaths and around $42 \%$ maternal deaths each year ${ }^{5}$. This can be reduced if all women give birth in a setting where skilled attendants can provide emergency obstetric care (EmOC) and life-saving neonatal interventions in the event of complications. Different studies identified inconsistent factors that affect institutional delivery service utilization such as individual, demographic, socioeconomic, and other characteristics of the mother, her family and the service environment ${ }^{4,6,7}$. 
The type of assistance a woman receives during childbirth has great impact on health of the mother and her baby. An important component of efforts to reduce health risks to mothers and kids is increasing the proportion of babies that are delivered in health facilities ${ }^{8}$. Predictors of safe delivery service use and the reasons for under utilization of the existing health service are not adequately investigated. Therefore, this study was designed to assess the predictors of institutional delivery service utilization in Dangila district, North West Ethiopia.

\section{Methods}

Setting

The study was conducted in Dangila district, North West Ethiopia. The district has a total population of 174,963, of whom $53.3 \%$ are women. The estimated annual deliveries are about 5,073 ; of which only $12 \%$ of mothers delivered at health institution. In the district, there are 6 health centers and 34 health posts. In these health facilities, the service is delivered by health officers, midwives, nurses and health extension workers? To increase institutional delivery, the Ethiopian government prepares transportation. This is done by assigning at least one ambulance per health institution. All maternal services are given free of charge to all women. Health extension workers have a list of pregnant and lactating mothers, and their address in their Kebele (smallest administrating unit).

\section{Study design and study population}

A community based cross-sectional study was conducted from February 01-28, 2015. Women who gave birth within the last one year prior to the study were included in the study.

\section{Sample size, sampling procedure and data collection}

A total sample size of 780 was calculated using single population proportion. We used a proportion of $18 \%$ institutional delivery ${ }^{10}, 95 \%$ confidence level and $4 \%$ marginal error. The sample size was multiplied by a design effect of 2 and added 10\% non-response rate.

Multi stage sampling was used. Five Kebeles were randomly selected. Women who gave birth within a year prior to this study were included using systematic random sampling. Women were interviewed at their home using pre tested and structured questionnaires. Three trained female diploma midwives collected the data. Two public health professionals were assigned as supervisor. Both data collectors and supervisors were trained on the purpose of the study, data collection technique and tool before and after pretest.

\section{Data processing and analysis}

Data was entered and analyzed using SPSS version 20. A frequency of each variable was calculated to check for outliers and missed values. Proportion of institutional delivery was determined. Logistic regression was done to analyze the data. Crude and adjusted Odds ratios were computed for each explanatory variable to determine the strength of association and control confounders. $P$ value $<0.2$ was taken as a cut-off point to select variables for the multiple logistic regression models. We used backward elimination to avoid multi collinearity. A p-value of less than 0.05 was considered statistically significant.

\section{Ethical consideration}

The study was approved by the Ethical Review Committee of Amhara Regional Health Bureau. Letter of permission was taken from respective administration. Written consent (finger print for those who cannot read and write) was taken from every woman. Privacy and confidentiality was maintained throughout the study period by excluding personal identifiers from the data collection form.

\section{Results}

Socio-demographic Characteristics of Participants

A total of 763 mothers were interviewed which made the response rate 97.8 percent. The mean $(+\mathrm{SD})$ age of respondents was $29.5 \pm 6.3$ years. All the respondents were orthdox Christian followers by religion, from Amhara ethnic group, married and rural residents. Majority of the respondents, $586(76.8 \%)$ and their husbands, $697(91.3 \%)$ were farmers. The average family size was five . Four hundred seventy six (62.4\%) mothers could not read and write. Whereas, $363(47.4 \%)$ of their husbands could not read and write (Table1). 
Table 1: Socio-demographic characteristics of respondents, Dangila district; Ethiopia, February 2015

\begin{tabular}{|c|c|c|}
\hline Variable & Frequency $(n=763)$ & Percentage \\
\hline \multicolumn{3}{|l|}{ Age of the mother } \\
\hline 15-19years & 18 & 2.3 \\
\hline 20-24years & 106 & 13.9 \\
\hline $25-29$ years & 263 & 34.5 \\
\hline 30-34years & 218 & 28.6 \\
\hline \pm 35 years & 158 & 20.7 \\
\hline \multicolumn{3}{|c|}{ Educational status of the mother } \\
\hline Unable to read and write & 476 & 62.4 \\
\hline Can read and write & 147 & 19.3 \\
\hline Primary education & 97 & 12.7 \\
\hline Secondary education & 43 & 5.6 \\
\hline \multicolumn{3}{|c|}{ Educational status of the husband } \\
\hline Unable to read and write & 272 & 35.7 \\
\hline Can read and write & 362 & 47.4 \\
\hline Primary education & 94 & 12.3 \\
\hline Secondary education & 35 & 4.6 \\
\hline \multicolumn{3}{|l|}{ Occupation of mother } \\
\hline House wife & 177 & 23.2 \\
\hline Farmer & 586 & 76.8 \\
\hline \multicolumn{3}{|l|}{ Occupation of the husband } \\
\hline Daily laborer & 25 & 3.3 \\
\hline Farmer & 697 & 91.3 \\
\hline Merchant and farmer & 41 & 5.4 \\
\hline \multicolumn{3}{|l|}{ Family size } \\
\hline$\leq 5$ & 470 & 61.6 \\
\hline$>5$ & 293 & 38.4 \\
\hline
\end{tabular}

Obstetric and maternal characteristics

Three hundred twenty seven $(42.8 \%)$ mothers were gravida one to three and $121(15.9 \%)$ had more than six gravidity. About half of the respondents (51.3\%) were between para one and three while 115(15.1\%) had more than six parities.
In this study, $472(61.9 \%)$ mothers planned place of delivery for their last pregnancy; of which $342(72.5 \%)$ planned to give birth at a health institution. Three hundred thirty six mothers $(71.2 \%)$ decided by themselves on their place of delivery (Table 2). 


\begin{tabular}{|c|c|c|}
\hline Variable & Frequency $(n=763)$ & Percentage \\
\hline \multicolumn{3}{|l|}{ Number of pregnancy (gravidity) } \\
\hline $1-3$ & 327 & 42.8 \\
\hline $4-6$ & 315 & 41.3 \\
\hline$>6$ & 121 & 15.9 \\
\hline \multicolumn{3}{|l|}{ Number of delivery(parity) } \\
\hline $1-3$ & 392 & 51.4 \\
\hline $4-6$ & 256 & 33.5 \\
\hline$>6$ & 115 & 15.1 \\
\hline \multicolumn{3}{|l|}{ Number of children } \\
\hline $1-3$ & 421 & 55.2 \\
\hline $4-6$ & 242 & 31.7 \\
\hline$>6$ & 100 & 13.1 \\
\hline \multicolumn{3}{|c|}{ Abortion(termination of pregnancy before 28} \\
\hline weeks of gestation) in life time & 89 & 11.7 \\
\hline Yes & 674 & 88.3 \\
\hline \multicolumn{3}{|l|}{ No } \\
\hline \multicolumn{3}{|l|}{ Still birth in life time } \\
\hline Yes & 140 & 18.3 \\
\hline No & 623 & 81.7 \\
\hline \multicolumn{3}{|l|}{ ANC visit } \\
\hline Yes & 511 & 66.9 \\
\hline No & 252 & 33.1 \\
\hline \multicolumn{3}{|c|}{ Gestational week at first ANC visit $(n=511)$} \\
\hline First trimester & 165 & 32.3 \\
\hline Second trimester & 291 & 56.9 \\
\hline Third trimester & 55 & 10.8 \\
\hline \multicolumn{3}{|l|}{ Number of ANC visit $(n=511)$} \\
\hline $1-3$ & 235 & 46.0 \\
\hline 4 & 242 & 47.4 \\
\hline$>4$ & 34 & 6.6 \\
\hline \multicolumn{3}{|l|}{ Plan place of delivery } \\
\hline Yes & 472 & 61.9 \\
\hline No & 291 & 38.1 \\
\hline \multicolumn{3}{|c|}{ Where did you plan to give birth? $(n=472)$} \\
\hline Health institution & 342 & 72.5 \\
\hline Home & 130 & 27.5 \\
\hline \multicolumn{3}{|c|}{ Decision maker about place of delivery $(n=472)$} \\
\hline The mother herself & 336 & 71.2 \\
\hline Her husband & 97 & 20.5 \\
\hline Her relatives & 39 & 8.3 \\
\hline \multicolumn{3}{|l|}{ ANC provider $(n=511)$} \\
\hline Health extension worker & 118 & 23.1 \\
\hline Nurse/midwife & 393 & 76.9 \\
\hline \multicolumn{3}{|c|}{$\begin{array}{l}\text { Discussion about place of delivery with } \\
\text { professionals }(n=511)\end{array}$} \\
\hline Yes & 400 & 78.3 \\
\hline No & 111 & 21.7 \\
\hline \multicolumn{3}{|c|}{ Assistant during last Delivery at home $(n=623)$} \\
\hline Family member & 156 & 25.0 \\
\hline Her friend & 25 & 4.0 \\
\hline TBA (Untrained) & 367 & 58.9 \\
\hline TBA(trained) & 76 & 12.1 \\
\hline
\end{tabular}

ANC - Antenatal Care; TBA - Traditional Birth Attendant

\section{Institutional delivery service utilization}

Of the total respondents, only $140(18.3 \%)$ gave birth at health facilities, and most of them $(81.7 \%)$ delivered at home. Only $76(12.1 \%)$ home deliveries were assisted by trained traditional birth attendant. Two third (66.9\%) of mothers attended Antenatal Care (ANC), of whom $276(54 \%)$ had more than three ANC visit (Table 2). 
Factors associated with institutional delivery service utilization

In this study, the bivariable logistic regression analysis showed that knowledge about danger signs, planned to give birth at a health institution, had ANC follow up during pregnancy, number of live birth, age, educational status, occupational status, husband occupation, husband education, time taken to arrive at health institution were statistically associated with institutional delivery service utilization.
In the multivariable logistic regression analysis, having sufficient knowledge about danger signs $[A O R=2.0$, 95\% CI: $(1.1,3.4)]$, Planned to give birth at health institution[AOR $=5.4,95 \%$ CI: $(3.0,9.6)]$, had ANC follow up during pregnancy [AOR=12.9, 95\% CI: $(5.0,33.3)]$ and taking less than one hour to reach nearest health institution $[\mathrm{AOR}=5.1,95 \% \mathrm{CI}:(2.9,9.1)]$ were positively associated with institution delivery service utilizatiin (Table 3).

Table 3-factors associated with institutional delivery among women, Dangila district; Ethiopia, February 2015

\begin{tabular}{|c|c|c|c|c|}
\hline \multirow[t]{2}{*}{ Factor } & \multicolumn{2}{|c|}{ Institutional delivery } & \multirow{2}{*}{$\begin{array}{l}\text { COR } \\
(95 \% \mathrm{c} / \mathrm{I})\end{array}$} & \multirow{2}{*}{$\begin{array}{l}\text { AOR } \\
(95 \% \mathrm{c} / \mathrm{I})\end{array}$} \\
\hline & Yes & No & & \\
\hline \multicolumn{5}{|c|}{$\begin{array}{l}\text { knowledge about danger signs during } \\
\text { delivery }\end{array}$} \\
\hline Sufficient knowledge & $53(7.0)$ & $129(16.9)$ & $2.3(1.5,3.4)$ & $2.0(1.1,3.4)$ \\
\hline Insufficient knowledge & $87(11.4)$ & $494(64.7)$ & 1.00 & 1.00 \\
\hline \multicolumn{5}{|c|}{ Plan to give birth at health institution } \\
\hline No & $\begin{array}{l}108(14.1) \\
32(4.2)\end{array}$ & $\begin{array}{l}234(30.7) \\
389(51.0\end{array}$ & $\begin{array}{l}5.6(3.6,8.5) \\
1.00\end{array}$ & $\begin{array}{l}5.4 \cdot 1(3.0,9.6) \\
1.00\end{array}$ \\
\hline \multicolumn{5}{|l|}{ ANC follow up } \\
\hline Yes & 134(17.6) & $377(49.4)$ & $14.5(6.3,33.5)$ & $12.9(5.0,33.3)$ \\
\hline No & $6(0.8)$ & $246(32.2)$ & 1.00 & 1.00 \\
\hline \multicolumn{5}{|l|}{ Number of delivery(parity) } \\
\hline 1 & $8(1.0)$ & $49(6.4)$ & 1.00 & \\
\hline $2-4$ & $109(14.3)$ & $418(54.9)$ & $1.5(0.7,3.4)$ & \\
\hline$>4$ & $23(3.0)$ & $156(20.4)$ & $0.9(0.3,2.1)$ & \\
\hline \multicolumn{5}{|l|}{ Having still birth } \\
\hline Yes & $22(2.8)$ & $118(15.5)$ & $1.2(0.7,2.0)$ & \\
\hline No & $118(15.5)$ & $505(66.2)$ & 1.00 & \\
\hline \multicolumn{5}{|l|}{ Educational status } \\
\hline Have no formal education & $83(10.9)$ & $540(70.8)$ & 1.00 & \\
\hline Primary education & $28(3.7)$ & $69(9.0)$ & $2.6(1.6,4.3)$ & \\
\hline Secondary education & $29(3.8)$ & $14(1.8)$ & $13.4(6.8,26.5)$ & \\
\hline \multicolumn{5}{|l|}{ Occupational status } \\
\hline Farmer & $79(10.4)$ & $507(66.4)$ & $3.3(2.2,4.9)$ & $3.2(1.8,5.4)$ \\
\hline Housewife & $61(8.0)$ & 116(15.2) & 1.00 & 1.00 \\
\hline \multicolumn{5}{|l|}{ Husband education } \\
\hline Have no formal education & $95(12.5)$ & $539(70.6)$ & 1.00 & 1.00 \\
\hline Primary education & $37(4.9)$ & $57(7.5)$ & $1.8(1.1,2.9)$ & $5.2(2.5,10.4)$ \\
\hline Secondary education & $8(1.0)$ & $27(3.5)$ & $4.4(2.6,7.6)$ & $4.6(1.6,12.6)$ \\
\hline \multicolumn{5}{|c|}{ Time taken to arrive at health institution } \\
\hline \multirow{2}{*}{$\geq 1$ hour } & 113(14.8) & $337(44.2)$ & $3.5(2.2,5.5)$ & $5.1(2.9,9.1)$ \\
\hline & $27(3.5)$ & $286(37.5)$ & 1.00 & 1.00 \\
\hline
\end{tabular}

ANC - Antenatal Care; COR- Crude odds ration; AOR - adjusted odds ratio, C/I- Confidence interval 


\section{Discussion}

This study aimed to assess factors associated with institutional delivery service utilization among mothers who gave birth in the last 12 months. Considering the last delivery a mother had, in this study, $18.3 \%$ of mothers gave birth at a health institution. This finding was consistent with study findings in Ethiopia ${ }^{10-13}$ and Bangla$\operatorname{desh}^{14}$.

On the other hand, this finding was lower than study findings elsewhere in Ethiopia ${ }^{15,16}$ and other developing countries such as Zambia, Uganda, Tanzania and Ne$\mathrm{pal}^{17-20}$. The difference might be due to the study area; the current study was done in a rural area, while the former studies included both rural and urban mothers. Beside this, discrepancies might be attributed to socio - economic difference of participants. Moreover, this might be due to the difference in access especially in terms of physical distance which is important to service utilization. This study was done among rural mothers; health insitutions are not in close proximity, even if the government arranges free transportation, the vehicle may not be available at the time they need it.

Knowledge about danger signs during delivery had statistically significant association with institutional delivery service utilization. Mothers who had sufficient knowledge about danger signs were 3 times more likely to give birth at a health institution compared with mothers who had insufficient knowledge. This finding was in agreement with study findings from Ethiopia and Kenya ${ }^{11,21,22}$. Knowledge is an important factor that affects attitude, intention and behavior. Women who have sufficient knowledge about delivery danger signs might have perceived service benefits of a health institution, like complication management by skilled health care workers in time of labor.

Mothers whose husbands had formal education were 5 times more likely to deliver at health institution than those mothers whose husbands had no formal education. This finding was consistent with study findings in South East Ethiopia, Nepal and Bangladesh ${ }^{16,23-25}$. Educated husbands might have better understanding about complications of home delivery and benefit of institutional delivery and assist their partner in deciding on place of delivery ${ }^{26}$. Other studies reported that partner support in decision making increases institutional delivery service utilization of mothers ${ }^{27}$.

Distance from the nearest health institution was significantly associated with institutional delivery service utilization. Women who travelled less than one hour walking distance to a nearby health facility were 3 times more likely to deliver at a health institution than women who spent more than 1 hour to access a health facility. Similarly, studies in low income countries such as Bahi District, Central Tanzania, Rural Zambia, Nepal, Rural Malawi and Rural India ${ }^{25,28-33}$ showed that physical distance is one of the major constraints that prevented community members from accessing and using trained attendants and institutional deliveries.

ANC service utilization was significantly associated with institutional delivery. Women who had ANC follow up were 13 times more likely to deliver at health institutions than their counterpart who had no ANC visits. This finding was consistent with study findings in Ethiopia, Nepal and Bangladesh ${ }^{11,16,23,25}$. Antenatal care visits offer a window of opportunity to get counseling services on the benefit of institutional delivery over home delivery. One component of focus ANC is counseling of the women about pregnancy, delivery and postnatal danger signs and importance of institutional delivery ${ }^{26}$.

Plan to give birth at health institution was another factor significantly associated with institutional delivery service utilization. Women who planned to give birth at a health institution were 5 times more likely to deliver at a health institution than their counter part. This study finding was in line with another study in Ethiopia ${ }^{34}$. Better birth preparedness being considered as an intervention fostering preventive behavior and influencing other socio-ecomnomic and cultural barriers, thus encouraging the use of health facilities.

Significant association was observed between institutional delivery service utilization and occupational status of the mother. In this study, farmers were 3.2 times more likely to give birth at a health facility than hosewives. This finding was not in agreement with study finding in Metekel Zone ${ }^{35}$. Currently, the government is working to increase institutional delivery service utilization by promoting maternal service utilization through professionals and mass media, and arranging transportation and free ANC delivery and postnatal service. Therefore, the discrepancy might be due to time gaps between studies. Farmers in the current study have the opportunity to get existing updated information than housewives, due to their outdoor exposure.

This study was limited to rural setting hence; results will not be generalized to the entire district. Since the study 
is cross-sectional, we could not establish a casual relationship of the explanatory and outcome variables.

\section{Conclusion}

Institutional delivery service utilization was very low. Knowledge about danger signs, husband education, p0lan to give birth at a health institution, had ANC follow up during pregnancy, and time taken to get nearby health institution, were factors associated with institutional delivery service utilization. Thus, the findings recommended repeated re-enforcement of institutional delivery service utilization through professionals. And also the findings recommend promotion of institutional delivery service utilization through mass media.

\section{Competing interests}

The authors declare that they have no competing interests

\section{Authors' contributions}

YMD and GBG conceived and designed the study, conducted statistical analysis and result interpretation, prepared manuscript. AAN assisted with data analysis and interpretation. All authors read and approved the manuscript.

\section{Acknowledgements}

We would like to thank the study participants for their participation. We were also grateful to express our gratitude to data collectors and supervisors for their time and full commitment.

\section{Reference}

1. Worldbank, WHO, UNFPA, UNICEF. Trends in maternal mortality :1990-2010. Geneva, Switzerland: 2012. 2. Wang W, Alva S, Wang S, Fort A. Levels and trends in the use of maternal health services in developing countries. DHS Comparative Reports No. 26. ICF Macro: Calverton, Maryland. 2011.

3. Dominic M, Gavin Y, Adam V, April H, Joanne Y. Where Do Poor Women in Developing Countries Give Birth? A Multi-Country Analysis of Demographic and Health Survey Data. . PLoS ONE. 2011;6(2): e17155 .doi:10.1371/journal.pone.0017155.

4. Central Statistical Agency [Ethiopia], ICFInternational. Ethiopia Demographic and Health Survey 2011. Addis Ababa, Ethiopia and Calverton, Maryland, USA: Central Statistical Agency and ICF International. 2012. 5. Lawn J, Lee A, Kinney M, Sibley L, Carlo W, Paul $\mathrm{V}$, et al. Two million intrapartum-related stillbirths and neonatal deaths: where, why, and what can be done? Internationl Journal of Gynaecology and Obstetrics 2009;107(1):S5-18, S9. doi: 0.1016/j.ijgo.2009.07.016. PMID: 19815202.

6. Gistane A, Maralign T, Behailu M, Worku A, Wondimagegn T. Prevalence and associated factors of home delivery in Arbaminch Zuria district, southern Ethiopia: Community based cross sectional study. Science Journal of Public Health. 2015;3(1):doi: 10.11648/j. siph.20150301.12.

7. Mehari AM. Levels and Determinants of Use of Institutional Delivery Care Services among Women of Childbearing Age in Ethiopia: Analysis of EDHS 2000 and 2005 Data. DHS WORKING PAPERS.ICF International Calverton, Maryland, USA. 2013.

8. Lancet. Home birth-proceed with caution.2010;376(9387):303.doi:10.1016/S01406736(10)61165-8.

9. Annual antenatal,delivery and postnatal service provision report, Dangila health Bureau, Dangila District, 2012.

10. AddisAlem F, Meaza D. Prevalence of institutional delivery and associated factors in Dodota Woreda (district), Oromia regional state, Ethiopia. Reproductive Health Journal 2012;9(33) :doi:10.1186/742-4755-9-33.

11. Alemayehu T, Fekadu M, Solomon M. Institutional delivery service utilization and associated factors among mothers who gave birth in the last 12 months in Sekela District, North West of Ethiopia: A community - based cross sectional study. BMC Pregnancy and Childbirth. 2012;12(74).

12. Gedefaw A, Muluken A, Tesfaye S. Factors associated with Institutional delivery service utilization among mothers in Bahir Dar City administration, Amhara region: acommunity based cross sectional study. Reproductive Health Journal. 2014;11(22).

13. Central Statistical Agency [Ethiopia]. Ethiopia Mini Demographic and Health Survey 2014. Addis Ababa, Ethiopia. 2014.

14. Kamal SMM. Preference for Institutional Delivery and Caesarean Sections in Bangladesh. Journal of Health and Population Nutrition 2013;31(1):96-109.

15. Worku A, Jemal M, Gedefaw A. Institutional delivery service utilization in Woldia, Ethiopia. Science Journal of Public Health. 2013;1(1):18-23.

16. Daniel B, Desalegn M. Institutional delivery service utilization and associated factors among child bearing age women in Goba Woreda,Ethiopia. Journal of Gynecology and Obstetrics. 2014:2(4):63-70.

17. Mwewa D, Michelo C. Factors associated with home 
deliveries in a low income rural setting-observations from Nchelenge district, Zambia. Medical Journal of Zambia 2010;37(4):235-38.

18. Jerome K, Per-Olof O, Eleanor T, Odberg P. Influence of Birth Preparedness, Decision-Making on Location of Birth and Assistance by Skilled Birth Attendants among Women in South-Western Uganda PLOS ONE. 2012;7(4): e35747. doi:10.1371/journal.pone.0035747.

19. Rose N, Japhet Z, Melkzedeck T, Siriel N, Albrecht J, Declare M, et al. Use pattern of maternal health services and determinants of skilled care during delivery in Southern Tanzania: implications for achievement of MDG-5 targets. BMC Pregnancy and Childbirth. 2007;7(29):doi:10.1186/471-2393-7-29.

20. Damaru PP. Pattern of Institutional delivery in Dadeldhura district of Nepal: A cross-sectional study. Journal of the Scientific Society. 2014;41(2):94-100.

21. Fantu A, Yemane B, Belaineh G. Factors associated with home delivery in Bahirdar, Ethiopia: A case control study BMC Research Notes. 2012;5(653).

22. Carol W, Moses M, Evans M, Gabriel M, Zipporah N. Delivery Practices and Associated Factors among Mothers Seeking Child Welfare Services in Selected Health Facilities inNyandarua South District, Kenya. BMC Public Health. 2011;11(360).

23. Nazrul I, Mohammad TI, Yukie Y. Practices and determinants of delivery by skilled birth attendants in Bangladesh. Reproductive Health 2014;11(86).

24. Abdella A, Abebaw G, Zelalem B. Institutional delivery service utilization in Munisa Woreda, South East Ethiopia: a community based cross-sectional study. BMC Pregnancy and Childbirth 2012;12(105).

25. Damaru PPM. Factors Influencing Delivery Service Utilization in Rural Areas of Dadeldhura District of Nepal. PARIPEX - Indian Journal of Reesearch. 2014;3(7):ISSN - 2250-1991.

26. Kihulya M, Elia MJ. Prevalence and predictors of institutional delivery among pregnant mothers in Biharamulo district, Tanzania: a cross-sectional study. Pan African Medical Journal. 2015;21(51).
27. Eshetu E, NigusseTadele. Determinants of Skilled Institutional Delivery Service Utilization among Women Who Gave Birth in the Last 12 Months in Bako District, Oromia, Ethiopia, 2012/13 (Case-Control Study Design). Journal of Gynecology and Obstetrics. 2015;3(2):3642.

28. Lwelamira J, Safari J. Choice of Place for Childbirth: Prevalence and Determinants of Health Facility Delivery Among Women in Bahi District, Central Tanzania. Asian Journal of Medical Sciences 2012;4(3):105-12.

29. Thaddeus S, Maine D. Too far to walk: maternal mortality in context Social Science Medicine. 1994;38(8):1091110.

30. Sabine G, Simon C, Jonathan C, Oona M. The Influence of Distance and Level of Care on Delivery Place in Rural Zambia: A Study of Linked National Data in a Geographic Information System PLoS Med 2011;8(1): e1000394. doi:10.1371/journal.pmed.

31. Line S, Johanne S, Jane C. Factors Influencing Women's Choice of Place of Delivery in Rural Malawi-an explorative study. REview African Sante Reprod. 2006;10(3):66-75.

32. Amy JK, John C,Andy S, Carine R. IRnesesatrciht aurtticileonal delivery in rural India: the relative importance of accessibility and economic status. BMC Pregnancy and Childbirth 2010;10(30):doi: 10.1186/471-239310-30.

33. Santosh K, Emily AD, Christopher JLM. Does distance matter for institutional delivery in rural India? Applied Economics 2014; 46(33):4091-103, DOI: 10.1080/00036846.2014.950836

34. FeyissaTesfaye R, Gebi AG. Determinants of Institutional Delivery among Childbearing Age Women in Western Ethiopia, 2013:Unmatched Case Control Study. PLoS ONE 2014;9(5):e97194. doi:10.1371/journal.pone.0097194.

35. Gurmesa T, Abebe Gm. Safe Delivery Service Utilization in Metekel Zone NorthWest Ethiopia. Ebtiopian Journal of Health Science. 2008;17(4):213-22. 